\title{
The Role of SPECT/CT in the Detection of Meckel's Diverticulum
}

\section{FJ Nasirova*}

Department of Radiology, Azerbaijan State Advanced Training İnstitute for Doctors Named After A. Aliyev, Baku, Azerbaijan

*Corresponding Author: FJ Nasirova, Department of Radiology, Azerbaijan State Advanced Training İnstitute for Doctors Named After A. Aliyev, Baku, Azerbaijan.
Received: September 09, 2021

Published: September 23, 2021

(C) All rights are reserved by FJ Nasirova.

\begin{abstract}
Meckel's diverticulum is considered a true because contain of all layers of the intestinal wall. There is a "rule of two". Meckel's diverticulum most often seen at 2 years of age and 2 times more common in males, is present in $2 \%$ of the population, often contains 2 ectopic tissues (gastric and pancreatic), is 2 inches long, is situated 2 feet from the ileocecal valve. The main clinical signs of Meckel's diverticulum are: melena, pain in the right lower quadrant of the abdomen, volvulus, intestinal obstruction. Surgery removal of diverticulum is recommended for bleeding develops. We reported the case of 20 children who had melena, the management was a scanning with Technetium ${ }^{99 m}$ - pertechnetate in the detection of Meckel's diverticulum.
\end{abstract}

Keywords: SPECT/CT; Meckel's Diverticulum; Technetium ${ }^{99 m}$

\section{Introduction}

Meckel's diverticulum is congenital anomaly caused by incomplete umbilical duct atrophy. Meckel's diverticulum presents in the fetus in the first months. The vitelline duct connects the growing fetus with the yolk sac. On the sixth-seventh week of the gestation it disappears. The development of Meckel's diverticulum is a consequence of the error of absorption of the vitelline duct, because the duct is not fully obliterated. Meckel's diverticulum represents $90 \%$ of all vitelline duct abnormalities. In 1700 a French physician and anatomist Alexis Littre described a strangulated diverticulum in an inguinal hernia [1], later this condition was named as Littre's hernia.

As the rule, Meckel's diverticulum is asymptomatic. Meckel's diverticulum is often symptomatic in first years of life. A Meckel's diverticulum may contain cells from both the stomach and pancreatic acini and also it contains ectopic mucosa in 50 to $100 \%$ of cases [2], colon mucosa, endometriosis or hepatobiliary tissue may be present [3]. Cells from the ectopic mucosa of stomach secrete acid, which promotes ulcer formation and bleeding. The likelihood of developing the disease decreases with increasing age. Although prevalence of Meckel's diverticulum is the same in males and females, but men are 2 - 3 times more likely to have complications.

In medicine there is the rule of two used for Meckel's diverticulum, which include:

- $2 \%$ of population,

- Ratio of male and female 2:1 respectively,

- 2 inches long located within,

- 2 feet of ileocecal valve, 
- And also contains 2 types of heterotopic mucosa (gastric and pancreatic),

- Symptomatic occur frequently at the age of 2 years.

This rule of two is recently disputed for easy memory by Felberbaun F., et al [4].

Main symptoms are pain in the right lower quadrant of the abdomen, gastrointestinal bleed in the stool (melena), vomiting sometimes, diverticulitis, Littre's hernia, obstruction of the bowel.

A common symptom is bleeding in children, which is caused by ulcers. Bowel obstruction is more common in adults. There was reported the case of a 24-year-old man who had an acute abdomen and treated by laparotomy with the detection diverticulitis of a Meckel's diverticulum [5]. Diagnosis of this disease based on the clinical picture is often difficult because the symptoms are nonspecific. $10 \%$ of symptomatic patient with undiagnosed Meckel's diverticulum diagnosis is confirmed during surgery [6]. Computed tomography is nonspecific, however may be more informative in diagnosis. The most helpful preoperative examination in the detection of Meckel's diverticulum is scanning with Technetium-99m pertechnetate (Tc99m-Pertechnetate), also called Meckel's scan.

Isotope scintigraphy can be considered the "gold standard" in the diagnosis of Meckel's diverticulum complicated by bleeding. The high diagnostic sensitivity of this method is based on the fact that in $95 \%$ of patients the bleeding diverticulum contains an ectopic gastric mucosa capable of accumulating the isotope. Normally, a high concentration of the isotope Tc99m-Pertechnetate is determined in the stomach and the bladder. A positive result about the diagnosis is made in the case of accumulation of an isotope in addition to these organs [7]. Tc $99 \mathrm{~m}$-Pertechnetate is absorbed by acidsecreting cells of the gastric mucosa. Most often, the accumulation of a radionuclide with a diverticulum is noted in the right lower quadrant of the abdomen [8].

The frequency of false-negative results when scanning Meckel's diverticulum is $1.7 \%$, false-positive results - $0.05 \%$ [9]. A falsenegative results of the study occur when there is an insufficient amount of gastric mucosa in the diverticulum. A false-positive conclusions occur in case of duodenal ulcer disease, intestinal vascular tumors. A rare complication of Meckel diverticulum is a tumor. But a tumor can occur mainly in adults.
Angiography can be performed in cases of lower gastrointestinal bleeding, but the bleeding should be active. Besides, the risk of scanning a radiation exposure is less than with X-ray examination $[10,11]$. The next step in the diagnosis of a bleeding diverticulum is laparoscopy, especially with negative scintigraphy findings and continuing bleeding $[12,13]$. During each diagnostic laparoscopy it is necessary to look for Meckel's diverticulum, particularly in the pediatric population with abdominal pain. Children with gastrointestinal bleeding, which there are the cause of Meckel's diverticulum, are very difficult to diagnose and for this reason Meckel's scan is a method of choice with an overall diagnostic accuracy of $92 \%$, sensitivity of $70 \%$ and specificity of $95 \%$ [14]. Active bleeding source from Meckel's diverticulum is identified in 32 out of 37 patients (85\%) by Meckel's scan, so correct diagnosis is reported by some authors [15].

Surgical treatment for Meckel's diverticulum consists in its resection (diverticulectomy) or in resection of a part of the ileum together with the diverticulum and subsequent enteroanastomosis. Patients recover completely after surgical treatment.

Thus, planar scintigraphy with Tc-99m pertechnetate is widely used in the diagnosis for gastrointestinal bleeding, which is the cause of Meckel's diverticulum. Additionally, single photon emission computed tomography/computed tomography (SPECT/CT) hybrid imaging can help to define positioning of the Meckel's diverticulum.

\section{Aim of the Study}

To define the role of the SPECT/CT method in the algorithm for examining patients with bleeding Meckel's diverticulum.

Our study group of 20 children comprises of 14 males and 6 females, ratio is 2,3:1 respectively (look at the table 1 ). The larger half of patients were aged about 2 years (range, 0 to 9 years). The control group was included 20 children with a mean age of 6 years, which had acute abdomen without melena.

Clinical case 1: 2-year-old male came to the study with presenting abdominal pain sometimes and anemia. Endoscopy was performed on a child before. Our result of Meckel's scan is shown in the figure 1. Despite the negative result of the endoscopic examination, yet the child was operated on. The patient has fully recovered on the $10^{\text {th }}$ postoperative day. 


\begin{tabular}{|c|c|c|c|c|c|}
\hline & $\begin{array}{c}\text { Variables } \\
(N=20)\end{array}$ & $\begin{array}{c}\text { Results } \\
\text { (\%) }\end{array}$ & $\begin{array}{l}\text { Symp- } \\
\text { toms }\end{array}$ & $\begin{array}{l}\text { Presenta- } \\
\text { tions }\end{array}$ & Numbers \\
\hline \multirow{3}{*}{ Age } & $\begin{aligned}<= & 2 \text { years } \\
& (10)\end{aligned}$ & $53 \%$ & \multirow{5}{*}{$\begin{array}{c}\text { GI bleed } \\
100 \%\end{array}$} & $\begin{array}{l}\text { Meckel's } \\
\text { scan }\end{array}$ & $\begin{array}{c}20 \\
(100 \%)\end{array}$ \\
\hline & $3-5$ years $(4)$ & $18 \%$ & & True Positive & $17(85 \%)$ \\
\hline & $>5$ years $(6)$ & $29 \%$ & & $\begin{array}{c}\text { False nega- } \\
\text { tive }\end{array}$ & $15 \%$ \\
\hline \multirow{2}{*}{ Gender } & Male (14) & $70 \%$ & & Sensitivity & $87 \%$ \\
\hline & Female (6) & $30 \%$ & & Specificity & $95 \%$ \\
\hline
\end{tabular}

Table 1: Demographic variables and presentations of diagnostic accuracy of Meckel's scan.
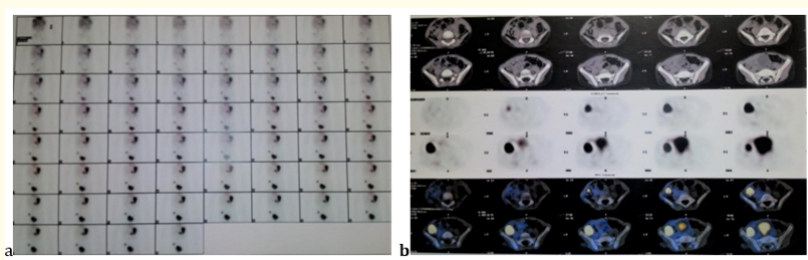

Figure 1: (a) $5 \mathrm{~min}$ and (b) $60 \mathrm{~min}$ after administration $1,2 \mathrm{mCi}$ intravenously of Tc-99 $\mathrm{m}$ pertechnetate, planar scan and axial of CT, scintigraphy, SPECT/CT hybrid images of the Meckel's diverticulum was performed respectively. Images showed a focal uptake of isotope in the small intestine region near the bladder on the right lower quadrant of abdomen.

Clinical case 2: 9-year-old female came to the study with presenting intermittent abdominal pain and melena. Our result of Meckel's scan is shown in the figure 2. Scintigraphy using Tc-99m Pertechnetate showed persistent focus of isotope (blue arrows) in the area to the right, above the bladder, which suggests the presence of heterotypic gastric mucosa.

For differential diagnosis of other causes of abdominal pain, a colonoscopy study is carried out, but the low region of bleeding in the small intestine cannot be determined with colonoscopy. Ultrasound is used as an auxiliary method. SPECT/CT hybrid images may be helpful for a final diagnosis. As well as hybrid images may provide to define position of the lesion.

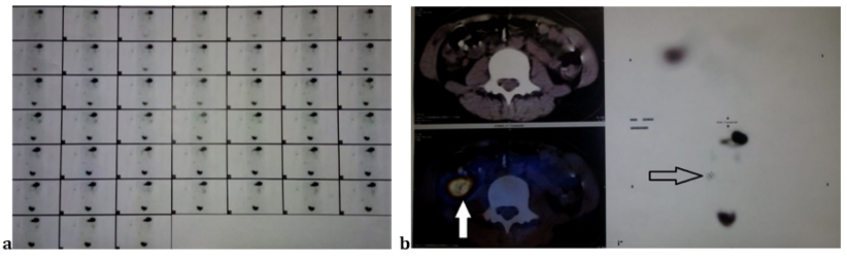

Figure 2: a: 5 min after administration $4 \mathrm{mCi}$ intravenously of Tc-99 m pertechnetate: (a) coronary projections. In addition to physiological accumulation in the stomach, the bladder and weak concentration in the kidneys, there is a pathological accumulation of isotope in the right middle abdomen near the umbilical cord. b: $60 \mathrm{~min}$ after administration $4 \mathrm{mCi}$ intravenously of Tc-99 m pertechnetate: (b) axial projections of CT, SPECT/CT hybrid images and scintigraphy. There is the visualization of a tubular formation (arrow) near to the loops of the distal part of the small intestine with an accumulating isotope.

In one-year-old child (one of three patients with a false-negative result) a micro-ulcer in the Meckel's diverticulum was detected during diagnostic laparoscopy. The rest two children were examined on Meckel's scan during the temporary remission. With our practical experience that Meckel's scan should be performed on patients with bleeding Meckel's diverticulum during the exacerbation of the disease.

We presented our data about the accuracy, sensitivity and specificity of the Meckel's scan method. These statistics are similar to other indicators of literary sources in table 1.

In figure 1 and 2 the presentation of two clinical cases clearly demonstrate the role of SPECT/CT scans different depths and levels in detecting localization of Meckel's diverticulum complicated by bleeding. The surgeon needs to know both the position and anatomical orientation of the environment where the organ is located for its successful removal. To optimize the benefits of the SPECT/ CT examination, it is necessary to prioritize between the amount of anatomical position needed information and minimizing exposure of radiation to the patients.

The algorithm for examining, the differential diagnosis of a child with abdominal pain and the important role of the SPECT/ 
CT method in the diagnosis of bleeding Meckel's diverticulum were presented in figure 3 .

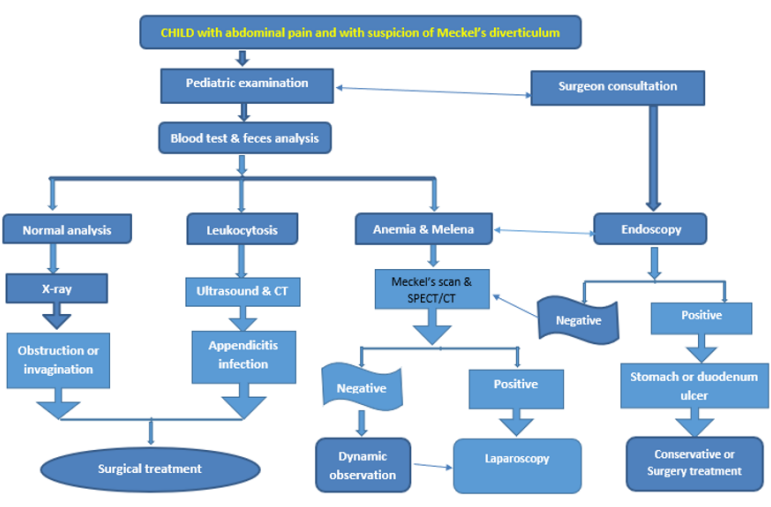

Figure 3: The algorithm.

\section{Conclusion}

Meckel's diverticulum has various presentations and cannot be easily diagnosed. Constant control is needed in child when Meckel's diverticulum is suspected. Persistent pain in the right area of the lower abdominal square and gastrointestinal bleeding were the main manifestation of this pathology. A negative Meckel's scan result has no predictive value. But it is taken as the basis in the diagnosis in cases of bleeding of Meckel's diverticulum. Simple and contrast X-ray examination, ultrasound and CT scanning in acute abdomen can be used as auxiliary methods in Meckel's diverticulum.

In our case, the study suggests that SPECT/CT imaging should be performed along with planar scintigraphy images to obtain a definitive diagnosis. Both laparoscopic diagnosis and laparoscopic treatment in cases of bleeding of Meckel's diverticulum have become widespread in medicine. During abdominal surgery, the intact Meckel's diverticulum, as accidental detection is usually removed to prevent possible complications. The question of removing other intact diverticulum of bowel remains rhetorical in accidental detection.

\section{Bibliography}

1. Turgeon DK and Barnett JL. "Meckel's diverticulum". The American Journal of Gastroenterology 85 (1990): 777-781.

2. Di Giacomo JC and Cottone FJ. "Surgical treatment of Meckel's diverticulum". Southern Medical Journal 86 (1993): 671-675.

3. Mackey WC and Dineen P. "A fifty-year experience with Meckel's diverticulum". Surgery, Gynecology and Obstetrics 156 (1983): 56-64

4. Felberwaver FX., et al. "The truth behind rule of two's and Meckel's diverticulum: revisited". European Surgery 39/5 (2007): 299-306.

5. Carlos Sanjuan-Sánchez and María G García-Rangel. "Meckel’s Diverticulum: Bibliography Review and Presentation of a Case". Gastrointestinal Disorders 3.5 (2020).

6. Yamaguchi M., et al. "Meckel's diverticulum investigation of 600 patients in the Japanese literature". The American Journal of Surgery 136 (1978): 247-249.

7. Podkamenev VV. "Pathology of Meckel's diverticulum in children". Russian Bulletin of Pediatric Surgery, Anesthesiology and Resuscitation 4 (2012): 28-33.

8. S Meculley., et al. "The value of Pertechnetatum Tc 99 Scans in the diagnosis of Meckel's diverticulum". Paediatric Surgery International 2 (1996): 240- 242.

9. Brown RL and Azizkhan RG. "Gastrointestinal bleeding in infants and children: Meckel's diverticulum and interstinal duplication". Seminars in Pediatric Surgery 8.4 (1999): 202-209.

10. Snyder CL. "Current management of umbilical abnormalities and related anomalies". Seminars in Pediatric Surgery 16.1 (2007): 41-49.

11. Akpinar Erhan., et al. "Life-threatening gastrointestinal system bleeding in Hodgkin disease". Diagnostic and Interventional Radiology 13 (2007): 87-89.

12. Sharma RK and Jain VK. "Emergency surgery for Meckel's diverticulum". World Journal of Emergency Surgery 27.3 (2008): $1-8$. 
13. Lee KH., et al. "Laparoscopy for definitive diagnosis and treatment of gastrointestinal bleeding of obscure origin in children". Journal of Pediatric Surgery 35.9 (2000): 1291-1293.

14. Chen-Chuan Huang., et al. "Diverse presentations in pediatric Meckel's diverticulum: a review of 100 cases". Pediatrics and Neonatology 55.5 (2014): 369-375.

15. D St-Vil., et al. "Meckel's diverticulum in children: a 20-year review". Journal of Pediatric Surgery 26.11 (1991): 1289-1292.

\section{Volume 4 Issue 10 October 2021}

(C) All rights are reserved by FJ Nasirova. 